\title{
Bioactivity and dissolution behavior of boron-containing bioactive glasses under static and dynamic conditions in different media
}

https://doi.org/10.1515/bglass-2019-0011

Received Oct 09, 2019; revised Nov 10, 2019; accepted Nov 11, 2019

Abstract: The present study reports the dissolution studies of a family of boron-doped bioactive glasses based on the composition ICIE16. Simulated body fluid (SBF), Trisbuffered solution and lactic acid were used as dissolution media for studies under static and dynamic conditions. The leaching of ions from the glasses under the evaluated conditions and media was compared and the bioactive behaviour of the glasses was evaluated. Influence of the incorporation of boron in the thermal properties of the glass was also analysed. Glasses exhibited faster bioactivity under dynamic dissolution configuration compared to static conditions. Moreover, the glass dissolution rate was faster in acidic conditions than in SBF or Tris solutions. It was found that at increasing boron content the dissolution of the glass is faster.

Keywords: Bioactive glasses, dynamic dissolution, bioactivity, boron, silicate glasses, lactic acid

\section{Introduction}

Bioactive glasses have been considered interesting materials for applications in bone and soft tissue engineering due to their characteristic of forming an interfacial bonding between the material and the body tissue [1, 2]. After implantation, bioactive glasses go through specific reactions that lead to the formation of a hydroxycarbonate

\footnotetext{
`Corresponding Author: Marcela Arango-Ospina: Department of Materials Science and Engineering, Institute of Biomaterials, University of Erlangen-Nuremberg, 91058 Erlangen, Germany; Email: marcela.arango@fau.de

*Corresponding Author: Aldo R. Boccaccini: Department of Materials Science and Engineering, Institute of Biomaterials, University of Erlangen-Nuremberg, 91058 Erlangen, Germany; Email: aldo.boccaccini@ww.uni-erlangen.de

Leena Hupa: Johan Gadolin Process Chemistry Centre, Åbo Akademi University, 20500 Turku, Finland
}

apatite layer (HCA) on the surface of the glass. Additionally, bioactive glasses release ions that could activate the expression of osteogenic genes and promote angiogenesis $[3,4]$. Since the discovery of Bioglass ${ }^{\circledR}$ by Hench et al. [5], research groups have been investigating the role of different oxides in the glass network to provide materials with larger thermal processing window compared to the $45 \mathrm{~S} 5$ glass while keeping the bioactive behaviour. Elgayar et al. [6] reported a series of silicate-based glasses, including the ICIE16 glass which has a similar composition to $45 \mathrm{~S} 5$ with potassium as additional network modifier. Different studies have reported the use of this glass for the preparation of scaffolds for bone tissue engineering [710].

Incorporation of therapeutic ions into bioactive glasses is of great interest due to the possibility to expand the properties of the material and promote additional beneficial effects, different biological active ions such as magnesium, zinc, strontium and boron have been studied as therapeutic agents in bone tissue engineering regarding the effect on osteoblast activity and angiogenesis [11, 12]. The biological effects of boron on the stimulation of wound healing, secretion of proangiogenic growth factors and upregulation of bone formation markers in vitro [13], make the incorporation of this ion into bioactive glasses interesting for potential applications in tissue engineering and regenerative medicine. Different studies have successfully reported in vitro and in vivo the effect of such materials on cellular activity and angiogenesis [14-17].

Characterisation of the dissolution process of bioactive glasses in aqueous solutions is carried out in terms of changes that occur not only on the surface of the glass but also in the solution. These experiments are normally conducted under static conditions, which could lead to local ion saturation and increased $\mathrm{pH}$ values [18], thus dynamic dissolution configurations are a convenient alternative to analyse the leaching behaviour of the glasses under a continuous solution flow. This study aimed to increase the understanding of the dissolution behavior of ICIE16 silicatebased bioactive glasses under different conditions and to

๑ Open Access. (c) 2019 M. Arango-Ospina et al., published by De Gruyter. Attribution 4.0 License 
Table 1: Chemical composition of experimental glasses (mol\%)

\begin{tabular}{ccccccc}
\hline Glass & $\mathrm{SiO}_{2}$ & $\mathrm{CaO}$ & $\mathrm{K}_{2} \mathrm{O}$ & $\mathrm{Na}_{2} \mathrm{O}$ & $\mathrm{P}_{2} \mathrm{O}_{5}$ & $\mathrm{~B}_{2} \mathrm{O}_{3}$ \\
\hline ICIE16 & 49.46 & 36.27 & 6.6 & 6.6 & 1.07 & - \\
4B ICIE16 & 45.46 & 36.27 & 6.6 & 6.6 & 1.07 & 4 \\
8B ICIE16 & 41.46 & 36.27 & 6.6 & 6.6 & 1.07 & 8 \\
\hline
\end{tabular}

elucidate the influence on thermal properties and dissolution behaviour of boron incorporation into the ICIE16 glass composition.

\section{Methods}

\subsection{Glass processing}

The nominal oxide compositions of the glasses evaluated in this study are shown in Table 1. ICIE16 bioactive glasses were prepared following the melt-quench route from analytical grade reagents including $\mathrm{NaCO}_{3}, \mathrm{~K}_{2} \mathrm{CO}_{3}, \mathrm{MgO}$, $\mathrm{CaCO}_{3}, \mathrm{H}_{3} \mathrm{BO}_{3}, \mathrm{CaHPO}_{4} \cdot 2 \mathrm{H}_{2} \mathrm{O}$ and commercial grade Belgian quartz sand $\left(\mathrm{SiO}_{2}\right)$. The reference glass was melted in Pt crucibles at $1420^{\circ} \mathrm{C}$ for $1.5 \mathrm{~h}$ and the boron-containing glasses at 1200 for $1.5 \mathrm{~h}$, all glasses were cast in graphite moulds and annealed at $520^{\circ} \mathrm{C}$ for $1 \mathrm{~h}$ followed by crushing and a second melting process to ensure homogeneity. Afterwards, annealed glass blocks were crushed and sieved to particles ranging from 300 to $500 \mu \mathrm{m}$. Particles were rinsed with acetone in an ultrasonic bath several times until the solution was clear in order to remove fine powder from the surface of the particles. After rinsing, the particles were dried at $60^{\circ} \mathrm{C}$.

\subsection{Characterisation techniques}

The glass transition temperature $\mathrm{T}_{g}$ and the crystallisation temperature $\mathrm{T}_{c}$ of the glasses were determined with differential scanning calorimetry, DSC (Netzsch STA 449 F1 Jupiter $\left.{ }^{\circledR}\right)$. The measurements were performed in platinum pans in $\mathrm{N}_{2}$ atmosphere on $50 \mathrm{mg}$ samples with particle size lower than $45 \mu \mathrm{m}$. A heating rate of $10^{\circ} \mathrm{C} / \mathrm{min}$ was set for all glasses until $1200^{\circ} \mathrm{C}$ for ICIE16 glass and $1050^{\circ} \mathrm{C}$ for the boron-containing glasses.

The sintering temperature $\mathrm{T}_{s i}$, deformation and $\mathrm{fu}$ sion temperatures $\mathrm{T}_{f}$ were estimated from the changes in sample shape and height by means of a hot stage microscope (HSM, Misura Expert Systems). Sample preparation was carried out by pressing glass particles $(<45 \mu \mathrm{m})$ into cylinders of $3 \mathrm{~mm}$ height and $2 \mathrm{~mm}$ diameter with a spring-loaded hand-press. Samples were heated to $500^{\circ} \mathrm{C}$ at $40^{\circ} \mathrm{C} / \mathrm{min}$ and then at $5^{\circ} \mathrm{C} / \mathrm{min}$ until fusion temperature $+50^{\circ} \mathrm{C}$ was reached. Images of samples were recorded every $5^{\circ} \mathrm{C}$. The curve obtained from the sample height as a function of temperature was used to determine the sintering temperature, the glass crystallisation domain and the fusion temperature.

The IR absorption spectra of the samples were obtained with Fourier-transform infrared spectroscopy (FTIR, IRAffinity-1S Shimadzu). Spectra were scanned in absorbance mode over a wavenumber range of 4000 to $400 \mathrm{~cm}^{-1}$ with 40 scans at a resolution of $4 \mathrm{~cm}^{-1}$.

$\mathrm{X}$-ray diffraction $(\mathrm{XRD})$ patterns were recorded using a diffractometer (Miniflex 600 HR, Rigaku, Japan) with a radiation source K- $\alpha$ line of copper at $1.54056 \AA$ over a $2 \theta$ range from $10^{\circ}$ to $60^{\circ}$ with a step size of $0.02^{\circ}$.

Scanning electron microscopy (SEM, Leo 1530; Leo, Oberkochen, Germany) and energy dispersive X-ray analysis (EDX, Thermo Scientific UltraDry, Thermo Scientific, Madison, WI) were used to analyse the cross-section of the glass particles and SEM (Auriga, Carl-Zeiss, Jena, Germany) to observe the surface morphology of the particles. Cross-section samples for SEM evaluation were prepared by casting the glass particles in epoxy followed by a polishing process ranging from coarsest to fine CarbiMet ${ }^{\mathrm{TM}}$ silicon carbide grinding papers of 280, 500 and 1000 grit size with a final polish of approximately $8.4 \mathrm{mi}-$ cron.

\subsection{In vitro dissolution studies}

Three media were used to investigate the dissolution of the glasses, namely simulated body (SBF), Tris-buffered solution (50mM) (Trizma base, Sigma-Aldrich) adjusted at $\mathrm{pH}$ 7.4 with $1 \mathrm{M}$ hydrochloric acid $(\mathrm{HCl})$ and $0.5 \mathrm{M}$ lactic acid solution. SBF was selected to moreover study the bioactivity of the glasses and was prepared according to the protocol of Kokubo et al. [19], Tris-buffered solution was used to identify the leaching ions of the glass without having the interference of other ions in solution during ICP-OES measurements and lactic acid was of interest to study the effect of an acidic environment on bioactive glasses. Two parallel 
tests were carried out for all experiments and for some time points more tests were performed. The standard deviation of the parallel results is shown on the plots reported in the figures. For static dissolution studies $75 \mathrm{mg}$ of glass particles were added in $50 \mathrm{ml}$ of medium, as reported in previous studies [20] and placed in an orbital shaker at $37^{\circ} \mathrm{C}$ with agitation at $90 \mathrm{rpm}$. After immersion of the particles at different time points the $\mathrm{pH}$ was measured, the supernatant was separated from the particles and analysed with inductively coupled plasma optical emissions spectrometer (ICP-OES, PerkinElmer Optima 5300 DV, Shelton, CT).

Dynamic dissolution studies were performed with a continuous flow-through-cell set-up as described in detailed elsewhere [21, 22]. The Teflon sample cell was filled with glass particles $(225 \pm 5 \mathrm{mg})$ and random packing was assumed, filters of $0.3 \mu \mathrm{m}$ pore size were renewed after each experiment to avoid sample contamination. A peristaltic pump fed the solution through the particles with a flow rate of $0.2 \mathrm{ml} / \mathrm{min}$ established to achieve laminar flow [22]. The temperature in all the experiments was set to $37 \pm 1^{\circ} \mathrm{C}$. Between experiments the peristaltic pump was calibrated to ensure the right flow rate, tubing was rinsed with diluted $\mathrm{HCl}$ and ultra-pure water and sample cells were cleaned in an ultrasound bath. The solution was periodically collected for ICP-OES analysis and $\mathrm{pH}$ measurements

\section{Results}

\subsection{Thermal properties}

Figure 1 presents the DSC thermograms and HSM sintering curves for all glasses. The characteristic temperatures obtained from both techniques are shown in Table 2. The glass transition temperature $\mathrm{T}_{g}$ was determined from the DSC curve at the inflexion point of the first endotherm [23], whereas the crystallisation temperature $\mathrm{T}_{c}$ was taken from the maximum of the exothermic peak.

\subsection{In vitro bioactivity}

Figure 2 summarises the FTIR results used to determine the presence of calcium phosphate ( $\mathrm{CaP}$ ) deposition on the glass particles after immersion in SBF. XRD patterns are also shown in Figure 2. The spectra show Si-O-Si stretch and Si-O-Si bending vibrational modes at around 1030 $\mathrm{cm}^{-1}$ and $470 \mathrm{~cm}^{-1}$, respectively. After 7 days immersion in SBF all glasses exhibited adsorption bands at approxi- mately $560 \mathrm{~cm}^{-1}$ and $605 \mathrm{~cm}^{-1}$ corresponding to P-O bending vibrations which could be attributed to HCA formation [24], but are also characteristic of the presence of orthophosphates, therefore XRD patterns were also evaluated. After 3 days immersion in SBF peaks at $2 \theta 32^{\circ}$ and $46^{\circ}$ were observed for both ICIE16 and 4B ICIE16 glasses and after 7 days for 8B ICIE16, these peaks are indicative of HCA formation [25].

The surface morphology of glass particles was evaluated with SEM. Figure 3 presents the surface changes of all glasses after immersion in SBF for 1, 3 and 7 days. Correlating the FTIR and XRD results with the images, after 7 days a cauliflower-like apatite structure is visible on all glass surfaces, after 3 days immersion the reference glass surface presents apatite formation while for the boron-containing glasses this occurs in a lower extent. After 1 day immersion it is possible to observe the deposition of layers on the surface of the glasses. After 7 days, mainly three regions are distinguishable, the bulk glass, followed by a thick silicarich layer and a thin CaP layer.

Ion concentrations during the dissolution process of the glasses were determined with ICP-OES, Figure 4 shows the dissolution profiles of $\mathrm{Si}, \mathrm{Na}, \mathrm{Ca}, \mathrm{K}, \mathrm{P}$ and $\mathrm{B}$ up to 2 weeks immersion of the glasses under static conditions. The results show that the silicon, calcium, sodium, potassium and boron contents in SBF supernatants increased as boron content in glass increased, while the phosphorous concentration decreased. Silicon concentrations increased with time up to 3 days immersion in SBF, afterwards the concentration was constant indicating the breakup of the silica network occurring after 3 days immersion. The fact that the phosphorus concentration decreased implies the formation of the CaP layer on the glass [26], the initial rate at which the phosphorous concentration decreased was observed to depend on the glass boron content being higher for 8B ICIE16 [27].

Plots of $\mathrm{pH}$ profiles of SBF supernatants as function of immersion time are depicted in Figure 5. The higher $\mathrm{pH}$ values were observed for increasing boron content in glass compositions, 8B ICIE16 reached values above 8 after 1 week incubation, while for the reference glass at the same time point a value below 7.8 was measured.

Continuous flow studies in SBF were carried out up to three days on the ICIE16 and 4B ICIE16 glasses. Figure 6 illustrates the formation of the different layers on the reference glass surface. In comparison to static measurements in SBF, after 3 days in contact with medium, a thicker CaP layer is visible, implying a faster bioactive behaviour of the glass under dynamic conditions.

As shown in Figure 7, FTIR spectra and XRD patterns demonstrate the formation of a HCA layer after 3 days 
Table 2: Thermal properties of bioactive glasses measured with DSC and HSM

\begin{tabular}{cccccccc}
\hline Glass & $\begin{array}{c}\mathrm{T}_{\mathbf{g}}\left({ }^{\circ} \mathbf{C}\right) \\
\text { DSC }\end{array}$ & $\begin{array}{c}\mathrm{T}_{\mathbf{c}}\left({ }^{\circ} \mathbf{C}\right) \\
\text { DSC }\end{array}$ & $\begin{array}{c}\mathrm{T}_{\text {si }}\left({ }^{\circ} \mathbf{C}\right) \\
\text { HSM }\end{array}$ & $\begin{array}{c}\mathbf{T}_{\mathbf{x i}}\left({ }^{\circ} \mathbf{C}\right) \\
\text { HSM }\end{array}$ & $\begin{array}{c}\mathbf{T}_{\mathbf{x f}}\left({ }^{\circ} \mathbf{C}\right) \\
\text { HSM }\end{array}$ & $\begin{array}{c}\mathbf{T}_{\mathbf{f}}\left({ }^{\circ} \mathbf{C}\right) \\
\text { HSM }\end{array}$ & $\begin{array}{c}\Delta \mathbf{T}_{=} \mathbf{T}_{\mathbf{x i}} \mathbf{T}_{\mathbf{g}} \\
\left({ }^{\circ} \mathbf{C}\right)\end{array}$ \\
\hline ICIE16 & 625 & 825 & 685 & 780 & 1050 & 1130 & 155 \\
4B ICIE16 & 598 & 800 & 660 & 720 & 1095 & 1240 & 122 \\
8B ICIE16 & 584 & 800 & 650 & 700 & 1100 & 1215 & 116 \\
\hline
\end{tabular}

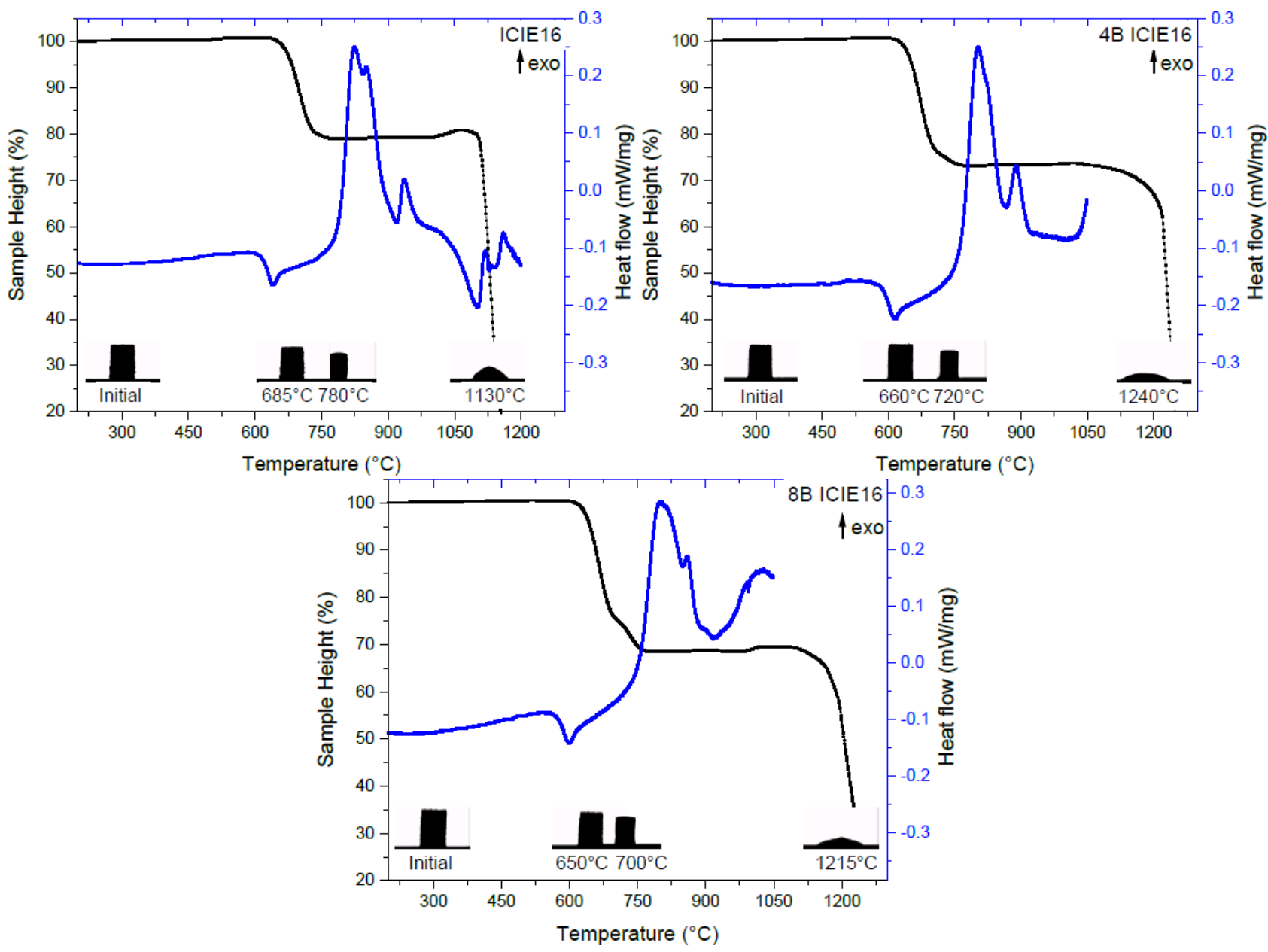

Figure 1: DSC and HSM curves for ICIE16, 4B ICIE16 and 8B ICIE16 glasses

immersion in SBF under dynamic conditions, more pronounced adsorption bands characteristic of HCA formation [24] are visible at $560 \mathrm{~cm}^{-1}$ and $605 \mathrm{~cm}^{-1}$ compared to static experiments. A change in the shape of the amorphous halo and peaks developing at $2 \theta 26^{\circ}$ and $32^{\circ}$ (typical of HCA) are recognisable from the XRD patterns. In relation to the results of the static set-up, a faster deposition of HCA is observed on the glasses under dynamic conditions.

\subsection{Dissolution studies}

\subsubsection{Dissolution studies in Tris under static conditions}

To evaluate the ion dissolution behaviour of all glasses without having any interference from the media with the ICP-OES measurement, Tris-buffered solution was selected. Samples were immersed in Tris under the same conditions as the previously described in vitro bioactivity studies in SBF. Figure 8, shows the cross-section image of ICIE16 glass particles after different immersion times in Tris. Similar to the results of dissolution studies in SBF, 


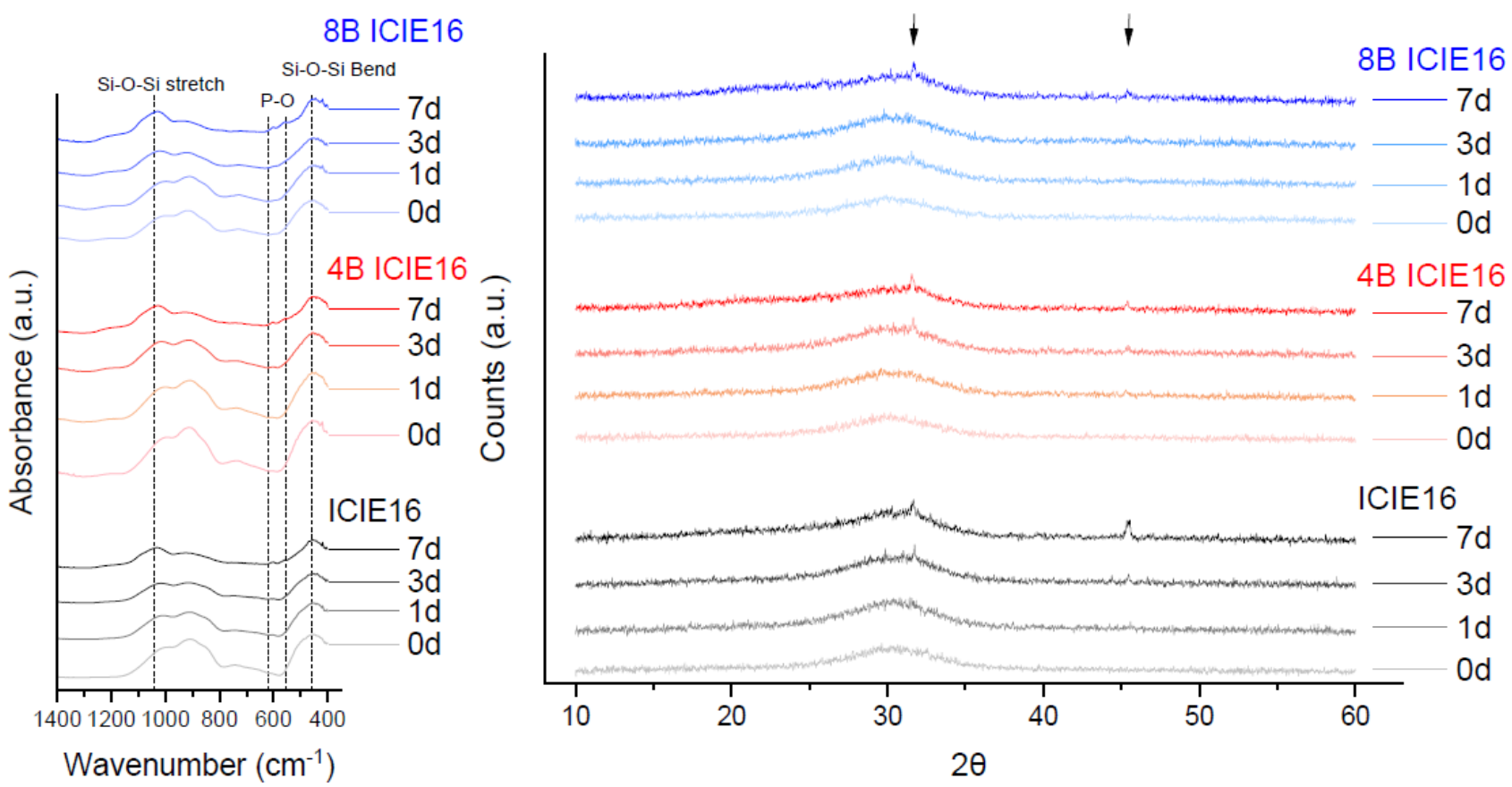

Figure 2: FTIR spectra and XRD patterns from all glass compositions after 0, 1, 3 and 7 days immersion in SBF under static conditions

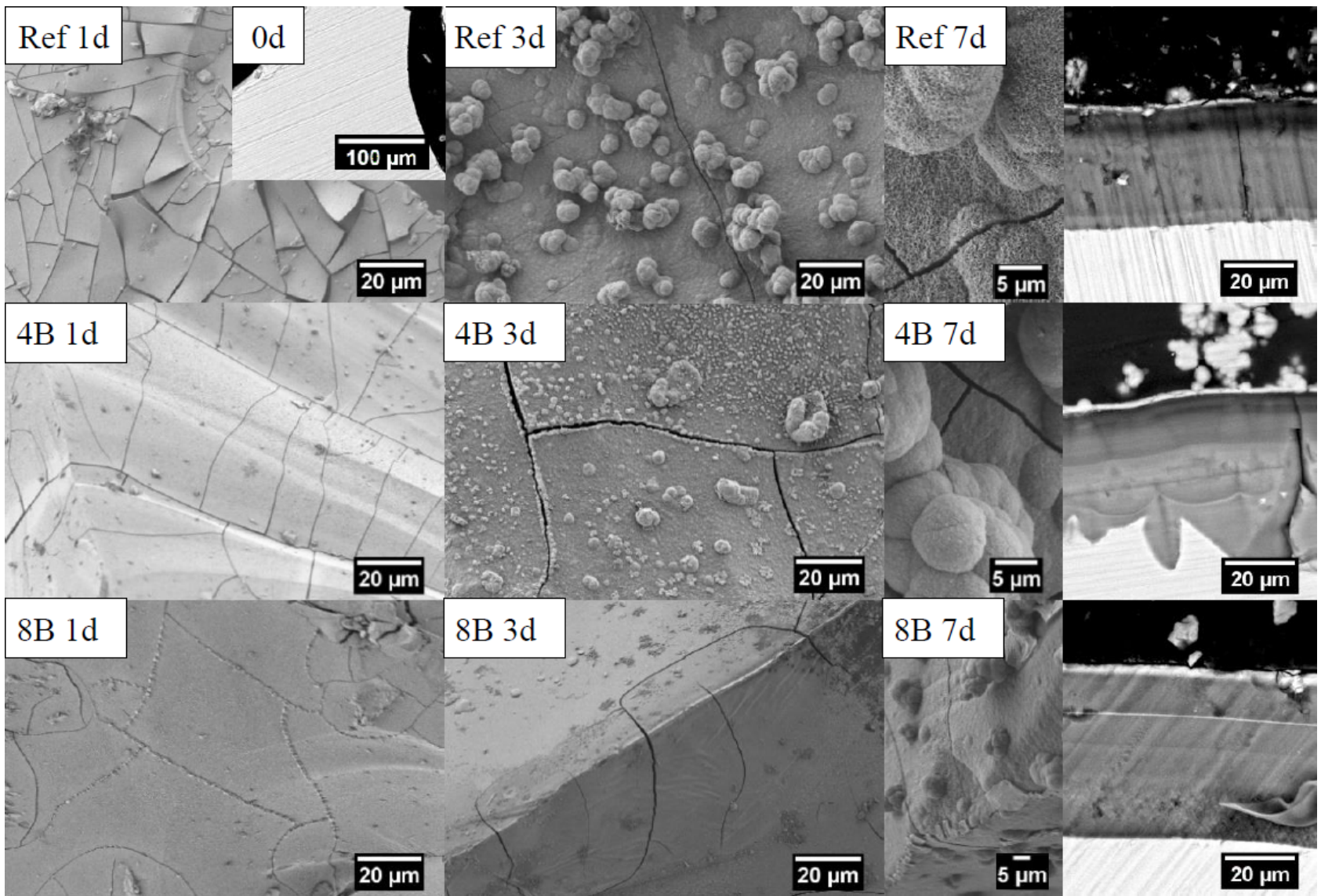

Figure 3: SEM images of glass particles after immersion in SBF during different times under static conditions showing the surface changes. Ref: ICIE16, 4B:4B ICIE16, 8B: 8B ICIE16 

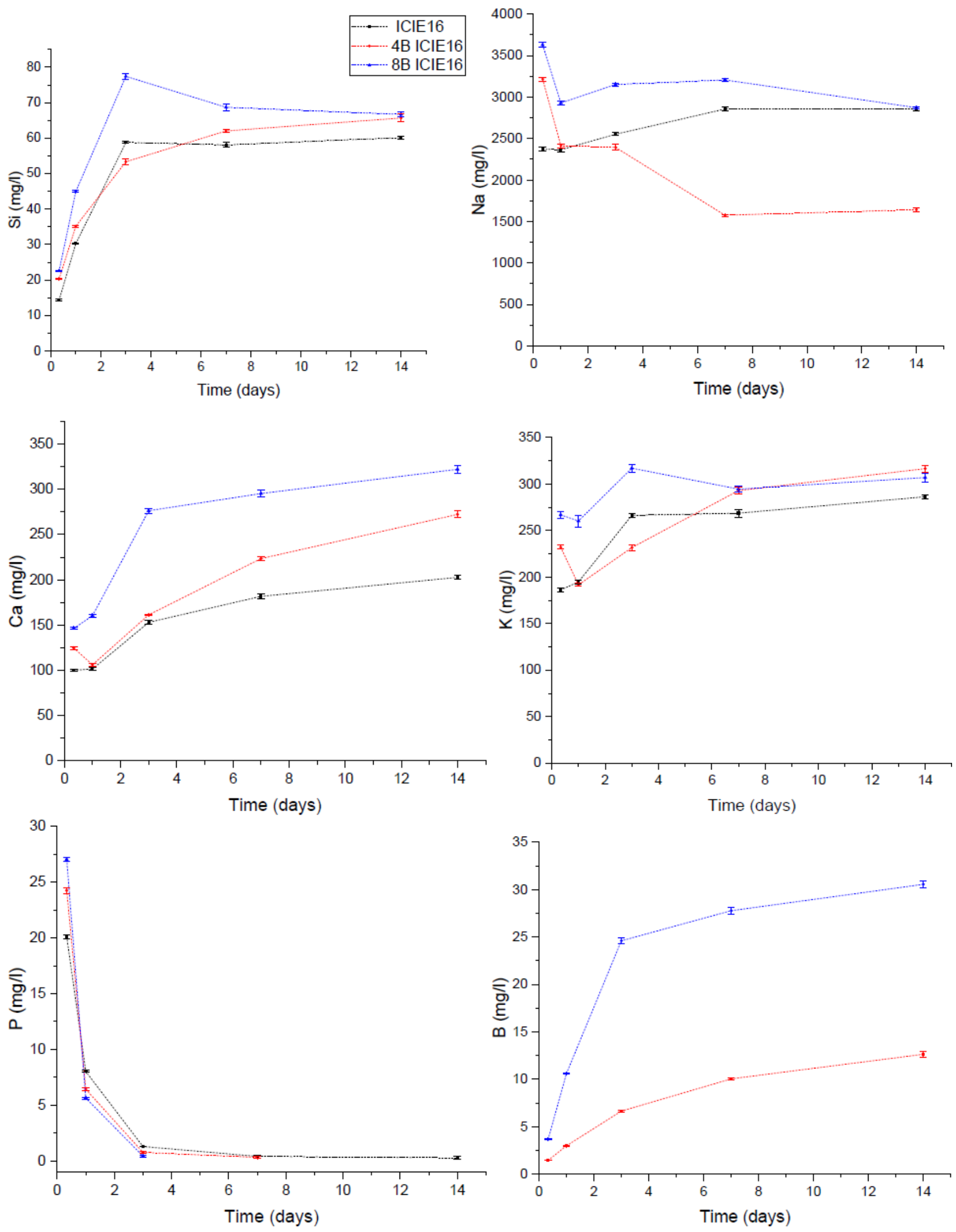

Figure 4: Ion dissolution profiles of ICIE16, 4B ICIE16 and 8B ICIE16 in SBF under static conditions as function of immersion time 

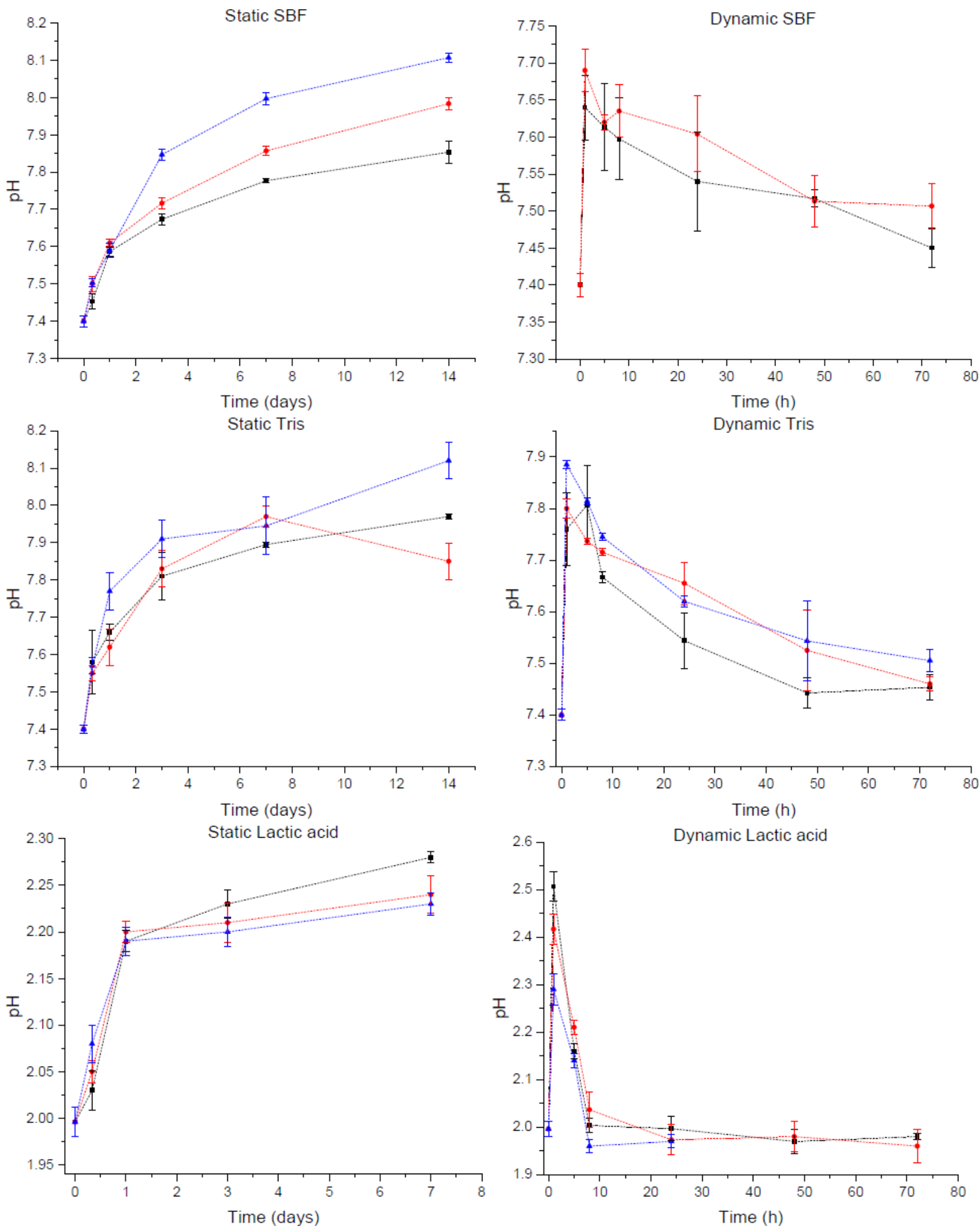

Figure 5: $\mathrm{pH}$ variation after immersion of the glasses in different media 


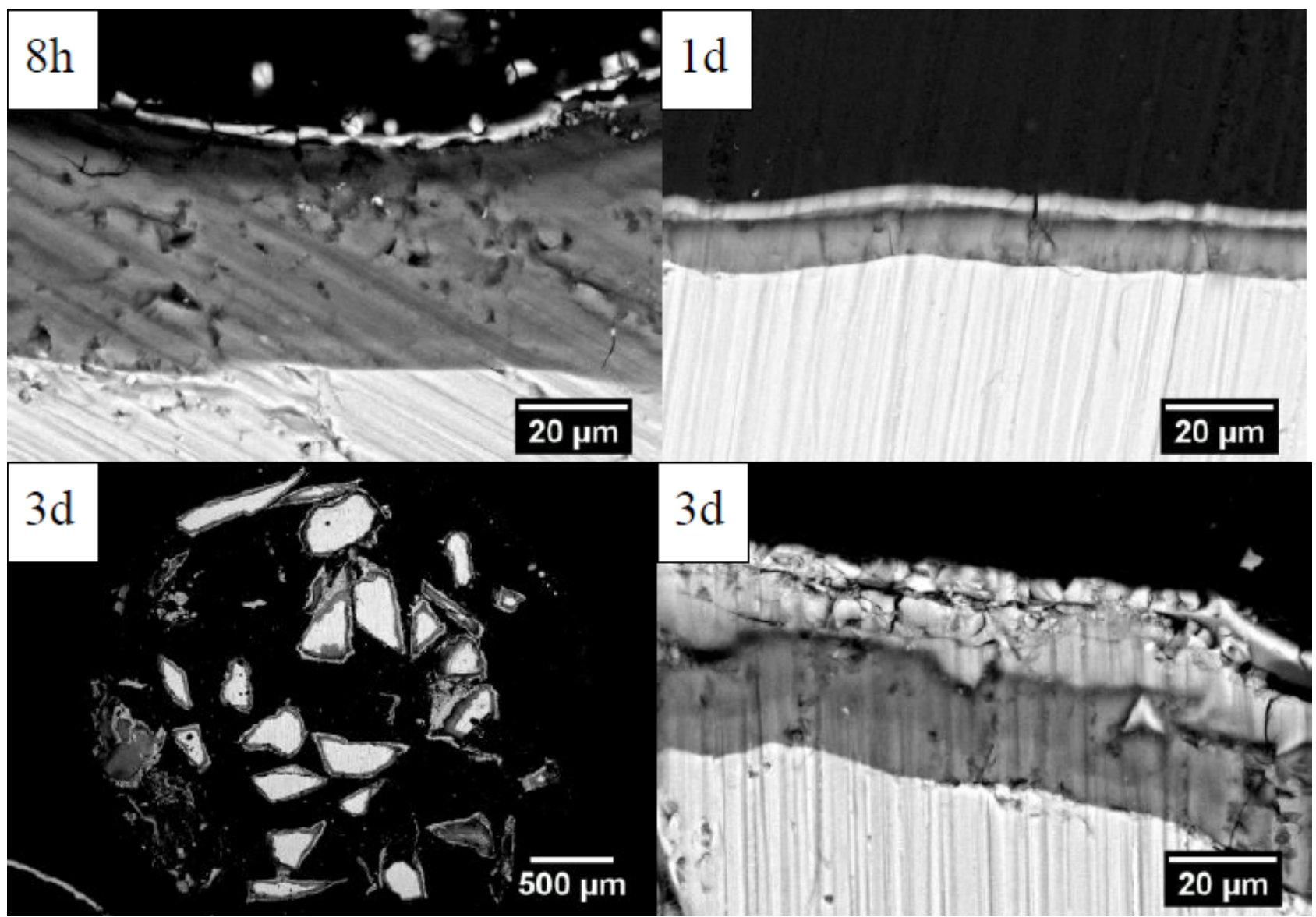

Figure 6: SEM images of cross-sectional surfaces of ICIE16 glass particles under dynamic dissolution studies in SBF after different immersion times

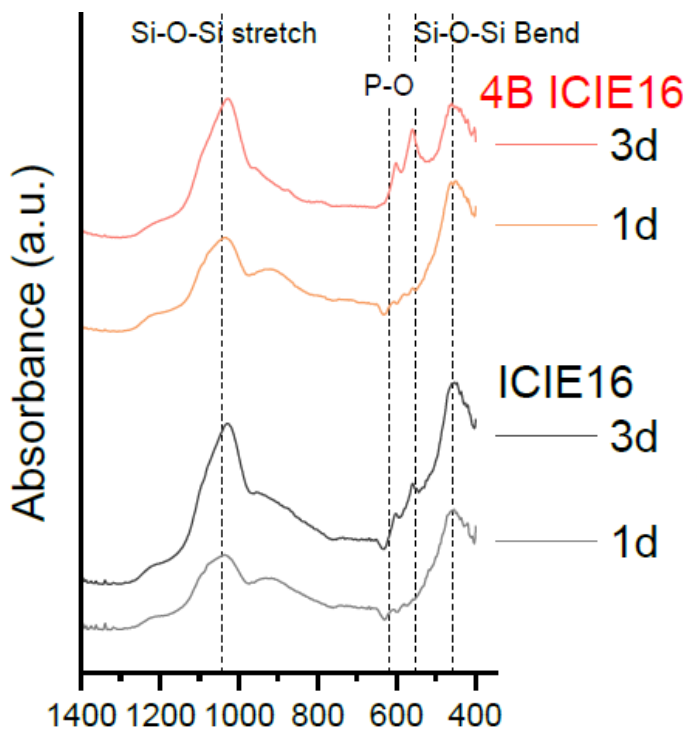

Wavenumber $\left(\mathrm{cm}^{-1}\right)$

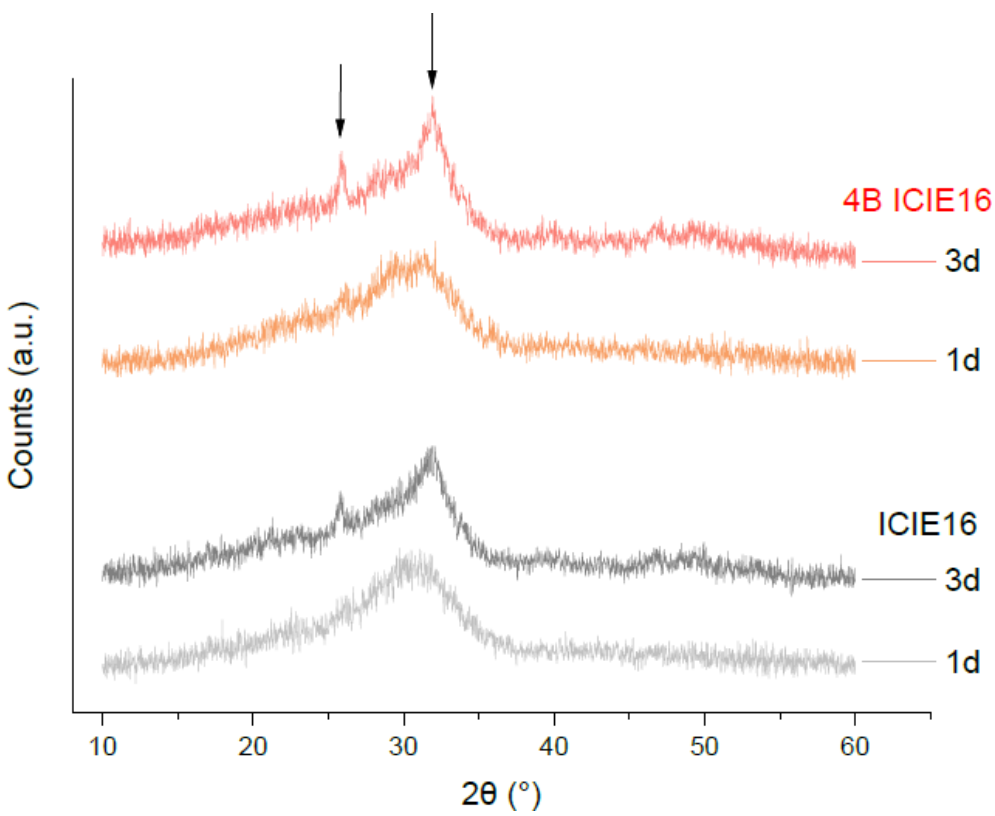

Figure 7: FTIR spectra and XRD patterns from ICIE16 and 4B ICIE16 after 1 and 3 days immersion in SBF under dynamic conditions 


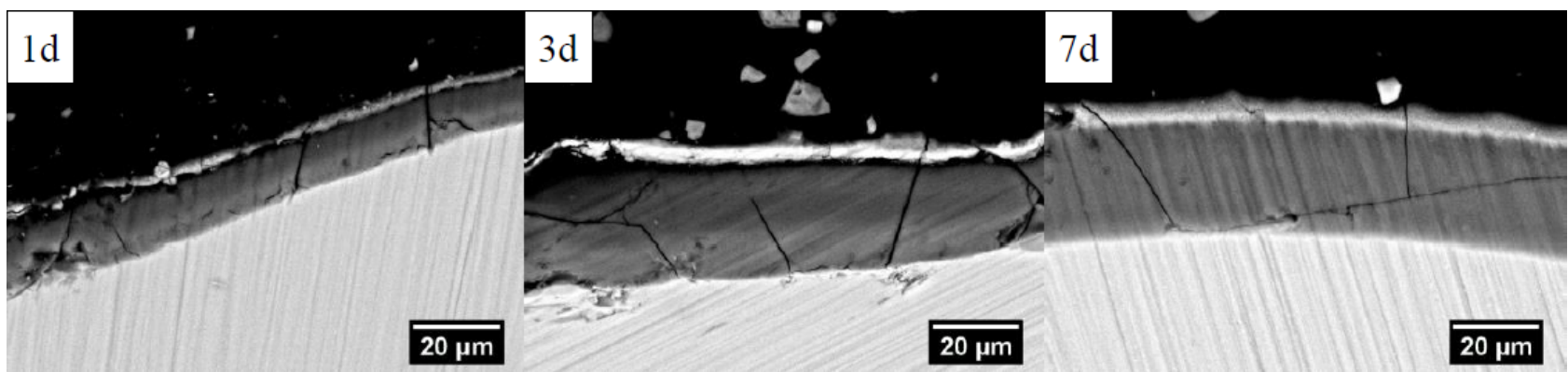

Figure 8: SEM images of cross-sectional surfaces of ICIE16 glass particles under static dissolution studies in Tris after different immersion times

three clear layers are observed. No distinct differences in the CaP layer thickness were noticed with immersion time.

As shown in Figure 5, the $\mathrm{pH}$ of the initial Tris solution increased from 7.40 to a maximum of 8.12 (8B ICIE16) after 14 days immersion. The glasses exhibit a fast release of silicon during the first 3 days immersion in Tris-buffered solution, it is noticeable that the fast release of all ions during the first hours corresponds to the glass with higher boron content (Figure 9). All glasses showed a similar $\mathrm{pH}$ increase during the first 24 hours. Subsequently, $\mathrm{pH}$ values increased with increasing boron content.

\subsubsection{Dissolution studies in Tris under dynamic conditions}

FTIR spectra of the glasses after 3 days immersion in Tris are shown in Figure 10, all characteristic vibrational bands for HCA previously mentioned are detected in all samples, additionally the presence of carbonate group can be distinguished corresponding to the peak around $800 \mathrm{~cm}^{-1}$ which could be assigned to the bending mode of $\mathrm{C}-\mathrm{O}$ [24].

The reference glass showed the higher concentration of silicon released in Tris, followed by the 8B ICIE16 glass, this trend was observed in all release profiles (Figure 11). It can also be observed that the fastest dissolution occurred during the first 8 hours, reaching a stable value after 24 hours immersion.

\subsubsection{Dissolution studies in lactic acid under static conditions}

Changes in $\mathrm{pH}$ values after static immersion of the glass particles in lactic acid can be seen in Figure 5. After 1 day immersion a fast $\mathrm{pH}$ increase occurred up to 2.20 for all glasses, the increment of $\mathrm{pH}$ is expected due to the dissolution of the glass. After 3 days immersion differences in $\mathrm{pH}$ values between samples are identified, the $\mathrm{pH}$ increased with decreasing boron content on the glasses, being the reference glass the composition with higher $\mathrm{pH}$ values after 7 days of around 2.28. Ion release profiles of lactic acid after immersion of the glasses are shown in Figure 12. The concentrations of calcium, potassium, sodium and phosphorus in the media reached maximum values during the first day of immersion, afterwards a stable concentration value for those ions was observed which might be an indication that the dissolution of the glass occurred mainly during the first 24 hours.

\subsubsection{Dissolution studies in lactic acid under dynamic conditions}

The $\mathrm{pH}$ values of the glass supernatants showed a fast increased during the first hour reaching a maximum value for the reference glass of approximately 2.5 followed by 2.4 and 2.3 for $4 \mathrm{~B}$ and $8 \mathrm{~B}$ ICIE16 glasses respectively. After 8 hours the $\mathrm{pH}$ reached a stable value of around 2 for all the samples. In accordance to the $\mathrm{pH}$ results, the concentration of ions in the media under dynamic conditions (Figure 13) indicated a fast dissolution of the glasses during the first 8 hours, reaching concentrations close to zero of all ions except for silicon.

\section{Discussion}

\subsection{Thermal properties}

The higher crystallisation temperature obtained for the reference glass in comparison to the boron containing samples, indicates the decrease of glass stability to crystallisation with addition of boron into the glass network. A decrease of $T_{g}$ and $T_{c}$ values was observed with increasing boron content, this is in agreement with the litera- 

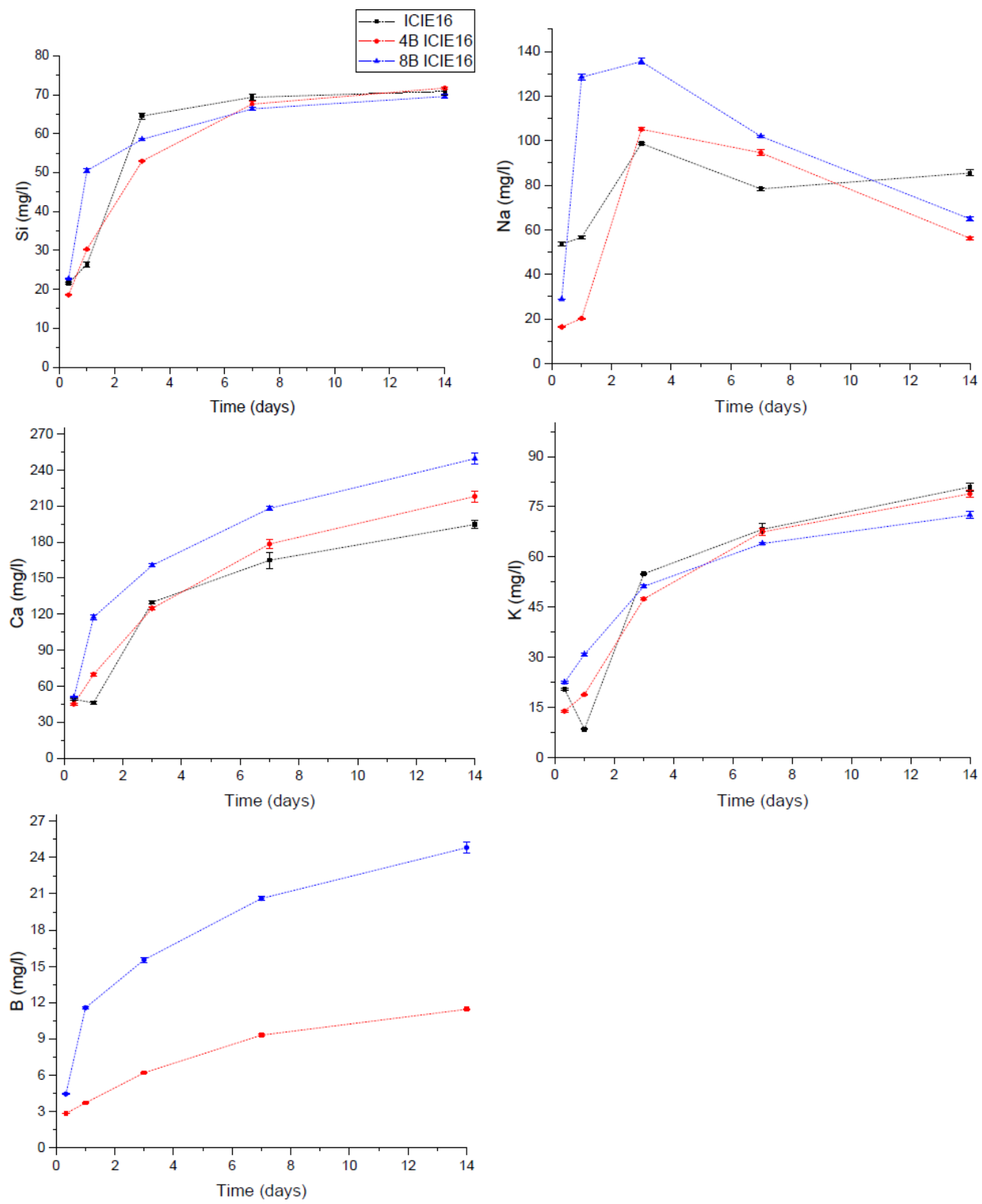

Figure 9: Ion dissolution profiles of ICIE16, 4B ICIE16 and 8B ICIE16 in Tris under static conditions as function of immersion time 


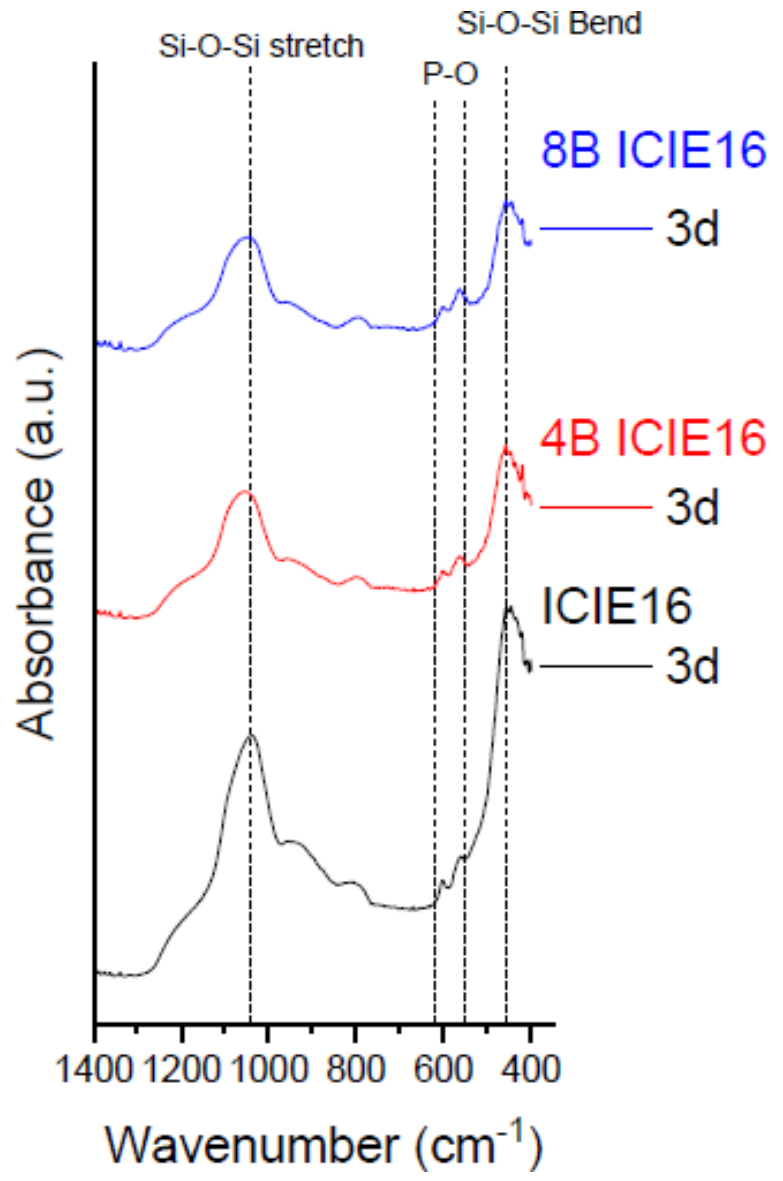

Figure 10: FTIR spectra of ICIE16, 4B ICIE16 and 8B ICIE16 glasses after 3 days immersion in Tris-buffered solution under dynamic conditions

ture [28] and might be an indication that the polymerisation of the silicate network results from the maintenance of the charge balance after network addition. From HSM data, all glasses showed single step sintering behaviour, the sintering temperature $\mathrm{T}_{s i}$ shifted to lower values with increasing $\mathrm{B}$ content. The glass crystallisation domain defined by the temperatures at the beginning and end of the plateau $\left(\mathrm{T}_{x i}\right.$ and $\mathrm{T}_{x f}$ ) was larger for samples with $\mathrm{B}$ compared to the reference glass; the beginning of crystallisation occurs at a higher temperature for the ICIE16 glass compared to the boron-containing samples, while the temperature at the end of the crystallisation process increased with increasing $\mathrm{B}$ content. The temperature difference $\Delta \mathrm{T}$ between the onset of crystallisation $\mathrm{T}_{x i}$ and $\mathrm{T}_{g}$ provides information of the glass thermal processing window and is an indication of the glass resistance to crystallisation upon heating. It is important to consider this temperature difference for the processing of glasses for instance into specific shapes such as 3D scaffolds without exhibiting crystallisation behaviour. $\Delta \mathrm{T}$ values for all glasses were greater than $100^{\circ} \mathrm{C}$ with a decreasing behaviour with increasing boron content.

\subsection{In vitro bioactivity}

Silica-based bioactive glasses are known for being reactive materials after being in contact with body fluids or analogous solutions. A series of reactions occur on their surface which leads to bone bonding, starting with a partial dissolution of the glass surface triggering the formation of a silica-rich layer and eventually the precipitation of amorphous calcium phosphate which then crystallises in HCA $[2,29,30]$. To evaluate the bioactive behaviour of glasses and the formation of a HCA layer on their surface, SBF solution has been commonly used since it contains a similar ionic concentration to human blood plasma [19]. In this study the bioactivity of ICIE16, 4B ICIE16 and 8B ICIE16 glasses was evaluated by soaking the glass particles in SBF solution under static and dynamic conditions. For the glass with the highest concentration of boron, the deposition of apatite like structures on the surface seems to be slower compared to the other compositions which is in disagreement with the literature in terms of the fast conversion to HA characteristic of borosilicate glasses [12, 27, 31]. Nevertheless, this rapid conversion has been shown for higher amounts of boron into the glass composition i.e. $25-75 \%$ compared to the 4 and $8 \mathrm{~mol} \%$ used in this study, therefore further structural characterisation of the glasses is needed to determine the role of B in the glass network and how it is affecting the apatite formation ability of the glass [32].

\subsection{Dissolution studies under static and dynamic conditions}

During the glass dissolution process an increase of the solution $\mathrm{pH}$ takes place due to the ion exchange mechanism between the cations from the glass and the protons of the solution, this $\mathrm{pH}$ change depends significantly on the glass dissolution rate $[26,33]$. The boron containing samples exhibited higher values of $\mathrm{pH}$ during the first hours of immersion in all dissolution media compared to the reference glass, which could be attributed to a faster dissolution behaviour.

As can be observed in Figure 14, after 1 day under continuous flow the thickness of the deposition layers on the surface of the ICIE16 glass is larger compared to the static results in Tris. Which could be an indication of the faster dissolution of the glass under dynamic conditions. In ac- 

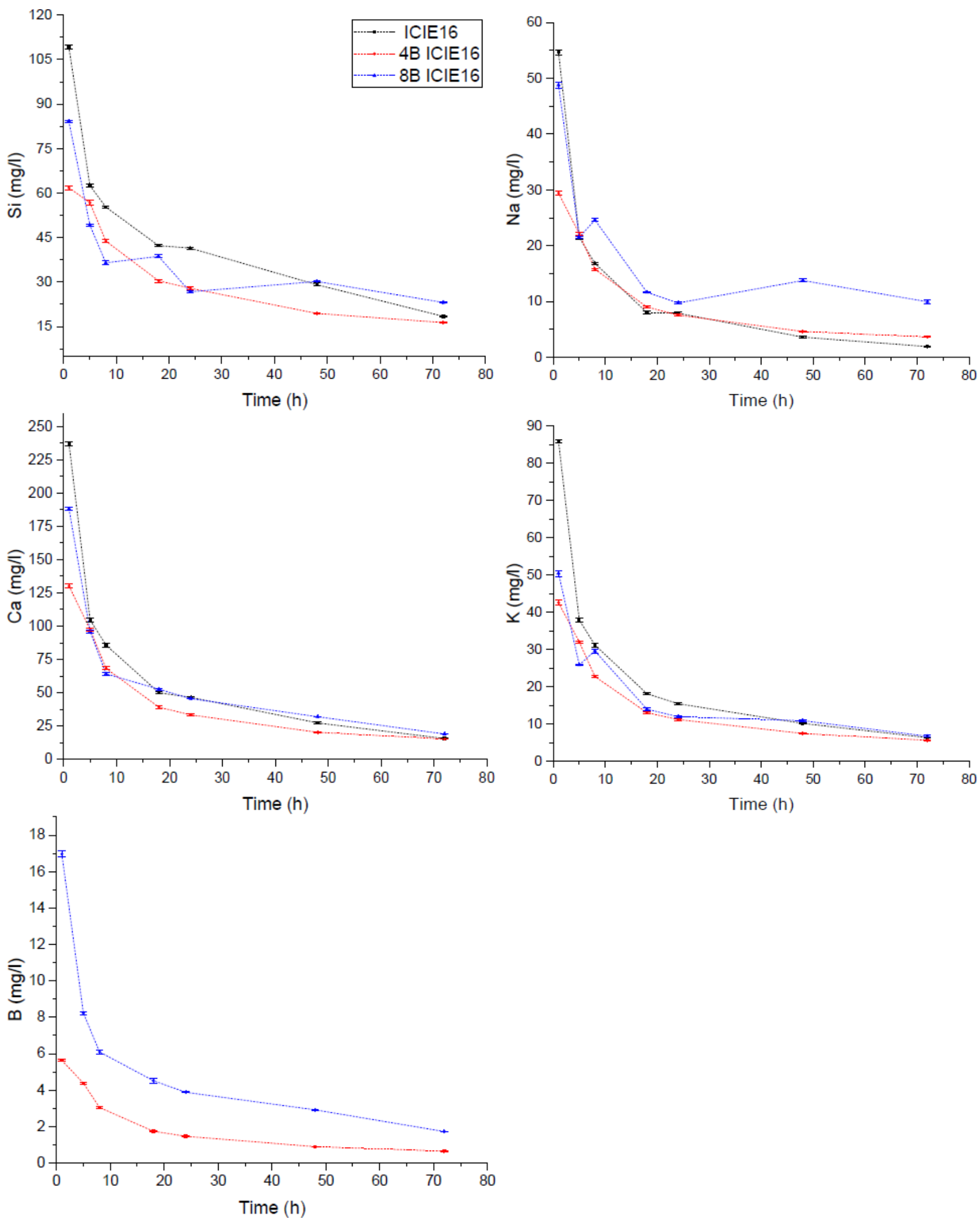

Figure 11: Ion dissolution profiles of ICIE16, 4B ICIE16 and 8B ICIE16 in Tris under dynamic conditions as function of immersion time 

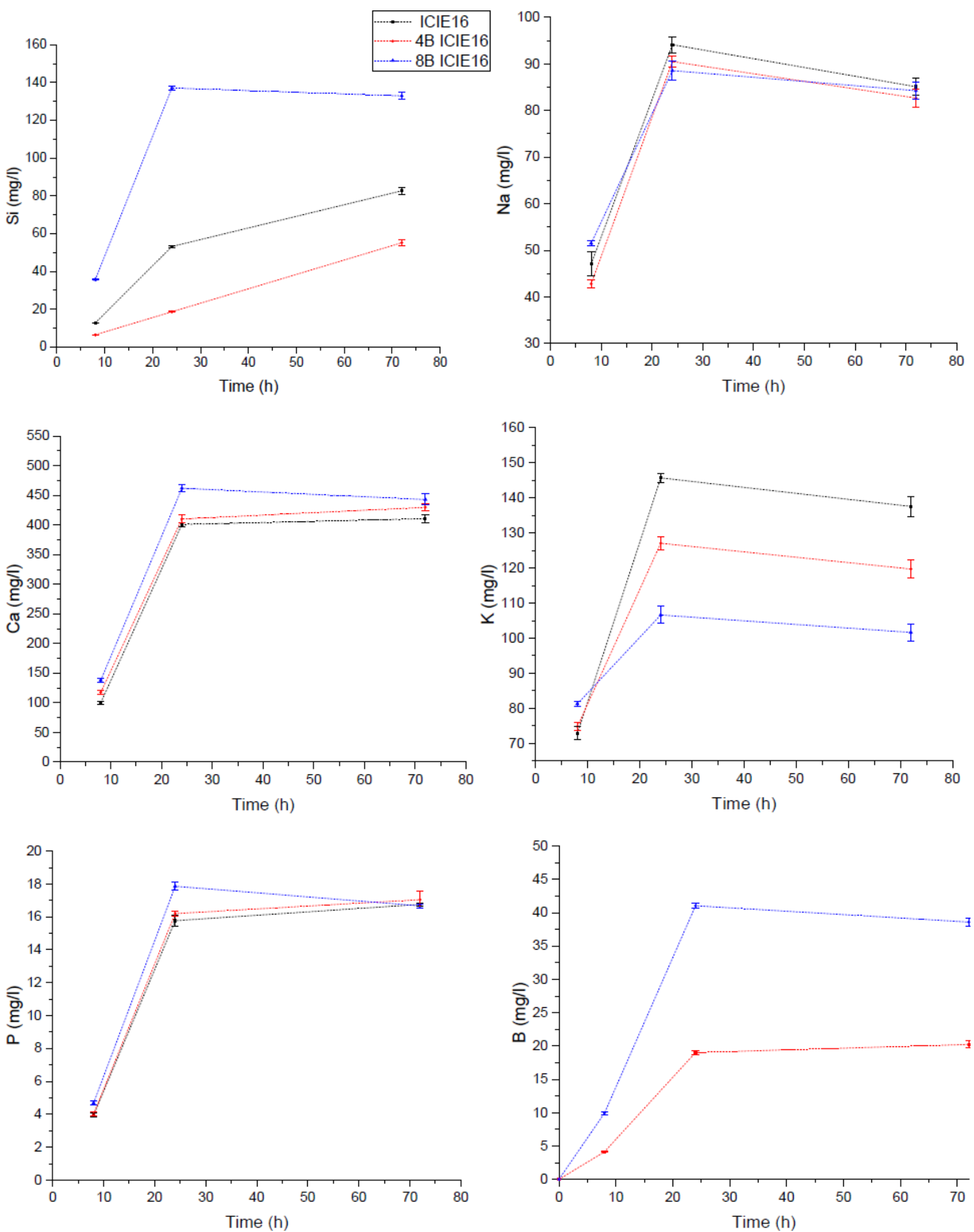

Figure 12: Ion dissolution profiles of ICIE16, 4B ICIE16 and 8B ICIE16 in lactic acid under static conditions as function of immersion time 

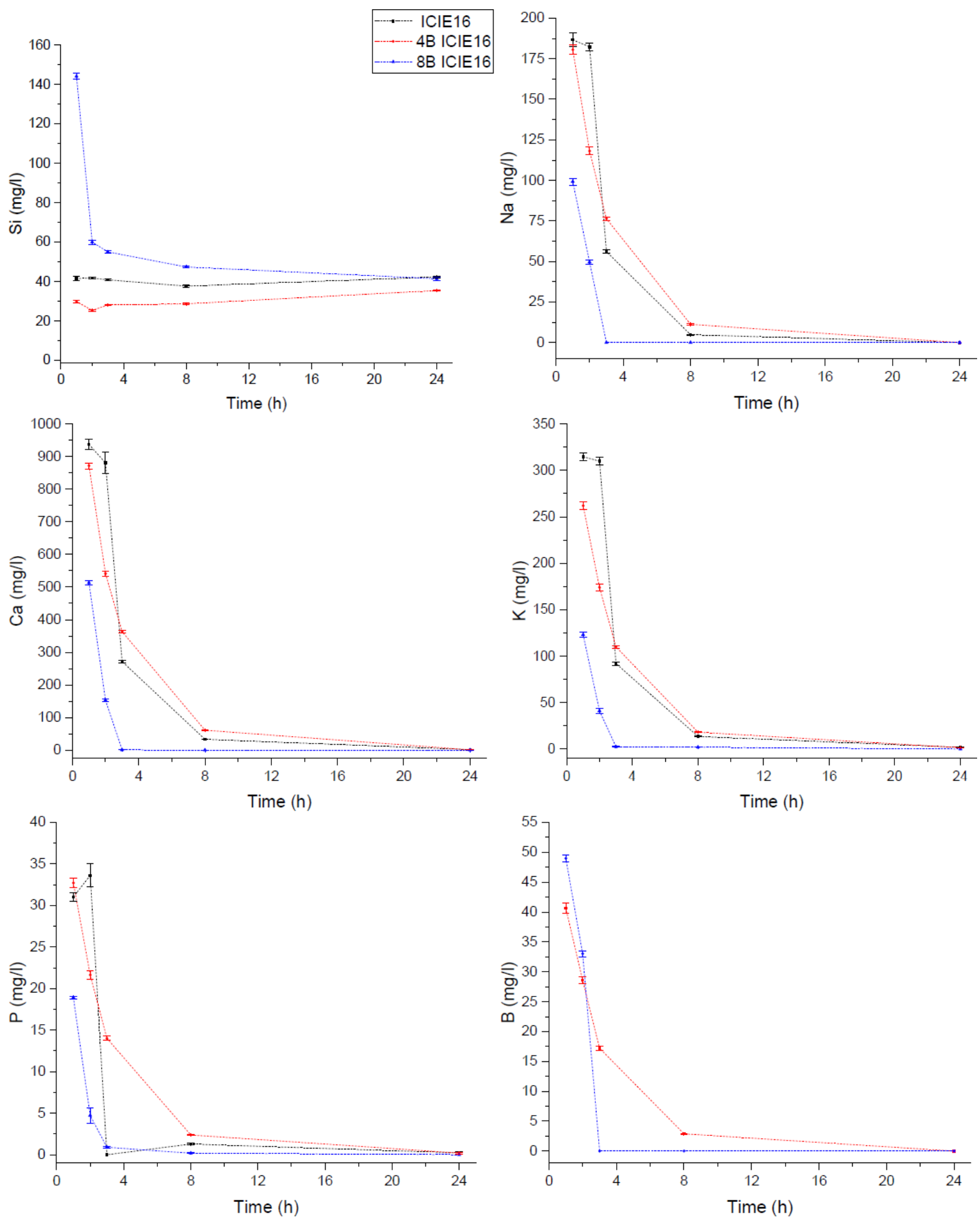

Figure 13: Ion dissolution profiles of ICIE16, 4B ICIE16 and 8B ICIE16 in lactic acid under dynamic conditions as function of immersion time 


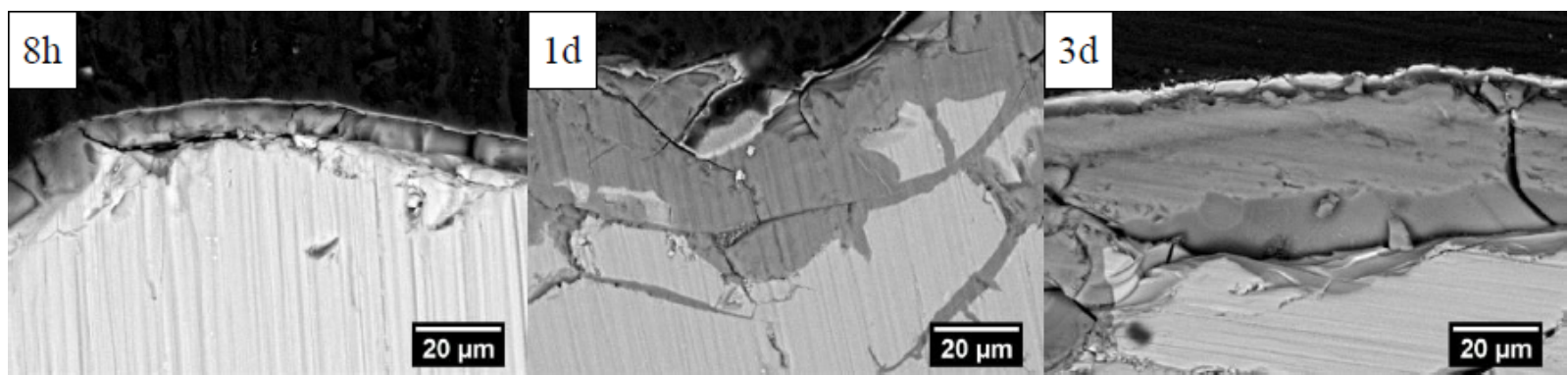

Figure 14: SEM images of cross-sectional surfaces of ICIE16 glass particles under dynamic dissolution studies in Tris after different immersion times

cordance with the ion release concentration profiles the silica network breakup occurred already after two days immersion compared to the three days under static conditions.

Solutions used for in vitro studies of bioactive glasses are generally set to $\mathrm{pH}$ values corresponding to the biological conditions in the human body, nevertheless few studies have reported the dissolution of bioactive glasses under acidic conditions [34-37]. The reason to use this kind of solution is to mimic conditions in which an acidic environment is locally developed, for example due to bacterial infections during implantation or when glasses are used in combination with polymers with degradation products that induce an acidic surrounding (i.e. PLA) [34, 35]. It is of interest to study the effect of such acidic environment on the dissolution of bioactive glasses, therefore lactic acid was used in this study. Compared to static dissolution studies, the dissolution of the glasses was faster under dynamic conditions which happened during the first 8 hours for the continuous flow set-up and during the first day for the static conditions. This information agrees with the higher $\mathrm{pH}$ values measured during the dynamic experiments compared to the values recorded under static conditions. Additionally, the dissolution in acidic conditions was shown to be dependent on the boron content of the glass compositions indicating that with increasing B content the glass dissolution is faster under both static and dynamic configurations.

\section{Conclusion}

Silicate-based bioactive glasses containing boron were successfully produced based on the reference glass ICIE16. Incorporation of boron in the silicate glass network induced changes in the thermal properties of the glass. The stability to crystallisation upon heating slightly decreased with boron content from 155 to $116^{\circ} \mathrm{C}$, consequently these materials are still suitable for application as 3D structures or coatings. The bioactivity of the glasses was evaluated by immersing the glasses in SBF under static and dynamic conditions. The reference glass showed a faster bioactive behaviour under dynamic conditions compared to the boron-containing glasses in both static and dynamic conditions. Glass dissolution studies in different media (SBF, Tris and lactic acid) under static and dynamic conditions were carried out to obtain information about the leaching kinetics and chemical resistance of the glasses. There was a similar dissolution behaviour of the glasses in Tris and SBF with similar $\mathrm{pH}$ increase. With increasing boron content in the glass composition, a faster glass dissolution in all media was obtained. In accordance with the literature [34, 37] the $\mathrm{pH}$ of dissolution media has a strong effect on the ion release of bioactive glasses, the ion release concentration profiles showed faster glass dissolution in acidic environments compared to solutions with physiological $\mathrm{pH}$ value.

Acknowledgement: The authors acknowledged the funding from Abo Akademi's Johan Gadolin Scholarship. The valuable technical assistance of Jaana Paananen, Luis Bezerra, Linus Silvander and Peter Backman for HSM, ICPOES measurements, SEM/EDX analysis and DTA measurements are respectively acknowledged.

Conflict of Interests: Authors state no conflict of interest regarding the publication of this paper.

Ethical approval: The conducted research is not related to either human or animals use.

\section{References}

[1] Miguez-Pacheco V., Hench L.L., Boccaccini A.R., Bioactive glasses beyond bone and teeth: Emerging applications in contact 
with soft tissues, Acta Biomater., 2015, 13, 1-15.

[2] Hench L.L., Chronology of Bioactive Glass Development and Clinical Applications, New J. Glas. Ceram., 2013, 03, 67-73.

[3] Jones J.R., Ehrenfried L.M., Hench L.L., Optimising bioactive glass scaffolds for bone tissue engineering, Biomaterials, 2006, 27, 964-973.

[4] Fu Q., Saiz E., Rahaman M.N., Tomsia A.P., Bioactive glass scaffolds for bone tissue engineering: state of the art and future perspectives, Mater. Sci. Eng. C, 2011, 31, 1245-1256.

[5] Hench L.L., Ceramics, glasses, and composites in medicine, Med. Instrum., 1973, 7, 136-44.

[6] Elgayar I., Aliev A.E., Boccaccini A.R., Hill R.G., Structural analysis of bioactive glasses. J. Non. Cryst. Solids, 2005, 351, 173-183.

[7] Sriranganathan D., Kanwal N., Hing K.A., Hill R.G., Strontium substituted bioactive glasses for tissue engineered scaffolds: the importance of octacalcium phosphate, J. Mater. Sci. Mater. Med., 2016, 27, 1-10.

[8] Nommeots-Nomm A., Labbaf S., Devlin A., Todd N., Geng H., Solanki A.K. et al., Highly degradable porous melt-derived bioactive glass foam scaffolds for bone regeneration, Acta Biomater., 2017, 57, 449-461.

[9] Nommeots-Nomm A., Lee P.D., Jones J.R., Direct ink writing of highly bioactive glasses. J. Eur. Ceram. Soc., 2018, 38, 837-844.

[10] Hatton J., Davis G.R., Mourad A.-H.I., Cherupurakal N., Hill R.G., Mohsin S., Fabrication of Porous Bone Scaffolds Using Alginate and Bioactive Glass, J. Funct. Biomater., 2019, 10, 15.

[11] Hoppe A., Güldal N.S., Boccaccini A.R., A review of the biological response to ionic dissolution products from bioactive glasses and glass-ceramics, Biomaterials, 2011, 32, 2757-2774.

[12] Balasubramanian P., Büttner T., Miguez Pacheco V., Boccaccini A.R., Boron-containing bioactive glasses in bone and soft tissue engineering, J. Eur. Ceram. Soc., 2018, 38, 855-869.

[13] O’Neill E., Awale G., Daneshmandi L., Umerah O., Lo K.W.H., The roles of ions on bone regeneration, Drug Discov. Today, 2018, 23, 879-890.

[14] Gorustovich A.A., López J.M.P., Guglielmotti M.B., Cabrini R.L., Biological performance of boron-modified bioactive glass particles implanted in rat tibia bone marrow, Biomed. Mater., 2006, 1, 100-105.

[15] Haro Durand L.A., Góngora A., Porto López J.M., Boccaccini A.R., Zago M.P., Baldi A., et al., In vitro endothelial cell response to ionic dissolution products from boron-doped bioactive glass in the SiO2-CaO-P2O5-Na2O system, J. Mater. Chem. B, 2014, 2 , 7620-7630.

[16] Haro Durand L.A., Vargas G.E., Romero N.M., Vera-Mesones R., Porto-López J.M., Boccaccini A.R. et al., Angiogenic effects of ionic dissolution products released from a boron-doped $45 \mathrm{~S} 5$ bioactive glass, J. Mater. Chem. B, 2015, 3, 1142-1148.

[17] Westhauser F., Widholz B., Nawaz Q., Tsitlakidis S., Hagmann S., Moghaddam A. et al., Favorable angiogenic properties of the borosilicate bioactive glass 0106-B1 result in enhanced in-vivo osteoid formation compared to 45S5, Bioglass. Biomater. Sci., 2019, C9BM01220F.

[18] Zhang D., Hupa M., Hupa L., In situ pH within particle beds of bioactive glasses, Acta Biomater., 2008, 4, 1498-1505.

[19] Kokubo T., Takadama H., How useful is SBF in predicting in vivo bone bioactivity? Biomaterials, 2006, 27, 2907-2915.

[20] Maçon A.L.B., Kim T.B., Valliant E.M., Goetschius K., Brow R.K., Day D.E. et al., A unified in vitro evaluation for apatite-forming ability of bioactive glasses and their variants, J. Mater. Sci. Mater.
Med., 2015, 26, 115.

[21] Taipale S., Ek P., Hupa M., Hupa L., Continuous Measurement of the Dissolution Rate of Ions from Glasses, Adv. Mater. Res., 2008, 39-40, 341-346.

[22] Fagerlund S., Ek P., Hupa L., Hupa M., Dissolution kinetics of a bioactive glass by continuous measurement, J. Amer. Ceram. Soc., 2012, 95, 3130-3137.

[23] Massera J., Hupa L., Hupa M., Influence of the partial substitution of $\mathrm{CaO}$ with $\mathrm{MgO}$ on the thermal properties and in vitro reactivity of the bioactive glass S53P4, J. Non. Cryst. Solids, 2012, 358, 2701-2707.

[24] Filgueiras M.R., La Torre G., Hench L.L., Solution effects on the surface reactions of a bioactive glass, J. Biomed. Mater. Res., 1993, 27, 445-453.

[25] Hench L.L., Roki N., Fenn M.B., Bioactive glasses: Importance of structure and properties in bone regeneration, J. Mol. Struct., 2014, 1073, 24-30.

[26] Jones J.R., Sepulveda P., Hench L.L., Dose-dependent behavior of bioactive glass dissolution, J. Biomed. Mater. Res., 2001, 58, 720-726.

[27] Huang W., Day D.E., Kittiratanapiboon K., Rahaman M.N., Kinetics and mechanisms of the conversion of silicate (45S5), borate, and borosilicate glasses to hydroxyapatite in dilute phosphate solutions, J. Mater. Sci. Mater. Med., 2006, 17, 583-596.

[28] Yang X., Zhang L., Chen X., Sun X., Yang G., Guo X. et al., Incorporation of $\mathrm{B} 203$ in CaO-SiO 2-P 205 bioactive glass system for improving strength of low-temperature co-fired porous glass ceramics, J. Non. Cryst. Solids, 2012, 358, 1171-1179.

[29] Jones J.R., Reprint of: Review of bioactive glass: From Hench to hybrids, Acta Biomater., 2015, 23, S53-S82.

[30] Martin R.A., Twyman H., Qiu D., Knowles J.C., Newport R.J., A study of the formation of amorphous calcium phosphate and hydroxyapatite on melt quenched Bioglass ${ }^{\circledR}$ using surface sensitive shallow angle X-ray diffraction, J. Mater. Sci. Mater. Med., 2009, 20, 883-888.

[31] Fabert M., Ojha N., Erasmus E., Hannula M., Hokka M., Hyttinen J. et al., Crystallization and sintering of borosilicate bioactive glasses for application in tissue engineering, J. Mater. Chem. B, 2017, 5, 4514-4525.

[32] Brauer D.S., Bioactive glasses - Structure and properties, Angewandte Chemie - Int. Ed., 2015, 54, 4160-4181.

[33] Brauer D.S., Karpukhina N., O’Donnell M.D., Law R.V., Hill R.G., Fluoride-containing bioactive glasses: Effect of glass design and structure on degradation, $\mathrm{pH}$ and apatite formation in simulated body fluid, Acta Biomater., 2010, 6, 3275-3282.

[34] Blochberger M., Hupa L., Brauer D.S., Influence of zinc and magnesium substitution on ion release from Bioglass $45 \mathrm{~S} 5$ at physiological and acidic pH, Biomed. Glas., 2015, 1, 93-107.

[35] Björkvik L., Wang X., Hupa L., Dissolution of Bioactive Glasses in Acidic Solutions with the Focus on Lactic Acid, Int. J. Appl. Glas. Sci., 2016, 7, 154-163.

[36] Schuhladen K., Wang X., Hupa L., Boccaccini A.R., Dissolution of borate and borosilicate bioactive glasses and the influence of ion $(\mathrm{Zn}, \mathrm{Cu})$ doping in different solutions, J. Non. Cryst. Solids, 2018, 502, 22-34.

[37] Björkvik L., Wang X., Hupa L., Dissolution of Bioactive Glasses in Acidic Solutions with the Focus on Lactic Acid, Int. J. Appl. Glas. Sci., 2016, 7, 154-163. 